\title{
Combined treatment with acetazolamide and medroxyprogesterone in chronic obstructive pulmonary disease patients
}

\author{
M. Wagenaar*, P. Je Vos*, Y.F. Heijdra*, L.J. Teppema\#, H.T.M. Folgering*
}

Combined treatment with acetazolamide and medroxyprogesterone in chronic obstructive pulmonary disease patients. M. Wagenaar, P. Je Vos, Y.F. Heijdra, L.J. Teppema, H.T.M. Folgering. (C) ERS Journals Ltd 2002.

ABSTRACT: Medroxyprogesterone acetate (MPA) and acetazolamide (ACET) are two ventilatory stimulants which are used in hypoxic and hypercapnic patients with chronic obstructive pulmonary disease (COPD).

In a double-blind randomised study, the effects of a 2-week treatment with MPA (30 mg b.i.d.) or ACET (250 mg b.i.d.), followed by a 2-week treatment with a combination of both drugs (MPA/ACET), on daytime and nocturnal ventilatory and blood gas parameters in 17 stable hypercapnic COPD patients were investigated.

ACET, MPA and MPA/ACET treatment decreased mean daytime carbon dioxide tension in arterial blood by $0.4,0.7$ and $1.2 \mathrm{kPa}$, respectively. Minute ventilation was improved only with combined therapy, from 9.3 to $11.2 \mathrm{~L} \cdot \mathrm{min}^{-1}$.

With MPA/ACET therapy, the hypercapnic and hypoxic ventilatory responses significantly increased, from 3.7 to $5.8 \mathrm{~L} \cdot \mathrm{min}^{-1} \cdot \mathrm{kPa}^{-1}$ and from -0.13 to $-0.40 \mathrm{~L} \cdot \mathrm{min}^{-1} \cdot \%{ }^{-1}$, respectively. The mouth exclusion pressure response to hypoxia increased during combination therapy, from -0.01 to $-0.03 \mathrm{kPa} \cdot \%^{-1}$. Nocturnal end-tidal carbon dioxide tension decreased with MPA and MPA/ACET treatment, by 0.9 and $1.4 \mathrm{kPa}$, respectively. MPA/ACET significantly increased mean nocturnal arterial oxygen saturation values, from 85.5 to $90.2 \%$.

The authors conclude that short-term combined treatment with medroxyprogesterone acetate and acetazolamide has a more favourable effect on day and night-time blood gas values and chemical drive than single drug treatment.

Eur Respir J 2002; 20: 1130-1137.
*Dept of Pulmonary Diseases, Dekkerswald, University of Nijmegen, Nijmegen, and ${ }^{\#}$ Dept of Physiology, Leiden University Medical Centre, Leiden, the Netherlands.

Correspondence: M. Wagenaar, Dept of Pulmonary Diseases, Dekkerswald, University of Nijmegen, P.O. Box 9001, 6560 GB Groesbeek, The Netherlands. Fax: 31246859290

E-mail: m.wagenaar@ulc.azn.nl

Keywords: Acetazolamide

chronic obstructive pulmonary disease hypercapnia

medroxyprogesterone acetate

Received: February 252002

Accepted after revision: July 22002

This study was funded by the Netherlands Asthma Foundation.
A subgroup of patients with severe chronic obstructive disease (COPD) are unable to maintain their blood gas values at normal levels. The life expectancy of these patients depends on both the severity of hypoxaemia and hypercapnia, although the latter is under debate [1]. Long-term oxygen $\left(\mathrm{O}_{2}\right)$ treatment improves the survival rate in these patients [2, 3], however, in some COPD patients, this will aggravate carbon dioxide $\left(\mathrm{CO}_{2}\right)$ retention [1]. It has been suggested that hypercapnic ventilatory failure is associated with reduced life expectancy in patients using long-term $\mathrm{O}_{2}$ therapy.

The goal of the treatment in this patient group is to avoid total respiratory failure. In the model of KARPEL and ALDRICH [4] respiratory failure is the result of a decrease in central respiratory drive, an excessive respiratory work load, inadequate respiratory muscle endurance and malnutrition. Therefore, noninvasive ventilation, supplemental $\mathrm{O}_{2}$, respiratory stimulants, inspiratory muscle training and nutritional support may be beneficial, although variable degrees of success have been reported [5-7].

The current study focuses on the effect of the respiratory stimulants acetazolamide (ACET) and medroxyprogesterone acetate (MPA), which can be used to increase the ventilatory drive and so avoid respiratory failure.

The carbonic anhydrase inhibitor ACET has been used successfully in the treatment of hypoventilation in COPD patients and for nocturnal hypoventilation [7-9]. By inhibiting renal carbonic anhydrase, ACET causes a metabolic acidosis that induces an increase in ventilatory drive. However, since ACET is present in many tissues and cells that are involved in the regulation of breathing, the effect of ACET on the control of breathing may be much more complicated. Previous animal studies by the current authors have shown a decrease in the slope and $\mathrm{x}$-intercept of the ventilatory $\mathrm{CO}_{2}$ response curve, which suggests that ACET $\left(4 \mathrm{mg} \cdot \mathrm{kg}^{-1}\right)$ may also act on the peripheral chemoreceptors and on the cerebral blood flow [10-12].

The synthetic progestagene MPA increases the $\mathrm{O}_{2}$ tension in arterial blood $\left(\mathrm{Pa}, \mathrm{O}_{2}\right)$ and reduces the $\mathrm{CO}_{2}$ tension in arterial blood $\left(\mathrm{Pa}, \mathrm{CO}_{2}\right)$ in COPD patients [7, $13,14]$. The ventilatory effect of MPA is mediated by receptors in the hypothalamus [15]. Ventilatory effects via the central and peripheral chemoreflex loops have also been described [12, 16]. VERBRAECKEN et al. [17] described a persistent ventilatory stimulation with 
ACET in patients with central hypoventilation, that lasted 1-6 months. The possible sustained effects of MPA and ACET are not known.

Simultaneous administration of both respiratory stimulants, to try and achieve a more efficient ventilatory stimulation in COPD patients, has not yet been described. The current authors hypothesised that stimulating both afferent systems to the ventilatory centres in the brainstem (chemoreceptor and hypothalamus) would yield a better ventilatory stimulation.

The aim of this study was to determine to what extent combined treatment with MPA and ACET ameliorates hypoxia and hypercapnia, and to compare the results with single drug treatment, in a group of hypercapnic COPD patients.

\section{Methods}

\section{Study design and patients}

Twenty-three hypercapnic outpatients with stable severe COPD, as defined by the European Respiratory Society (ERS) [18], were enrolled in this study. Inclusion criteria were: a daytime $P \mathrm{a}, \mathrm{CO}_{2}$ of $\geqslant 6.0 \mathrm{kPa}$ and ventilatory pump reserve. The latter was measured prior to supplying the respiratory stimulants by a voluntary hyperventilation test with capnography. Exclusion criteria were: nonstable COPD (i.e. exacerbation in the last 3 months), long-term $\mathrm{O}_{2}$ treatment, abnormal renal and liver functions, use of respiratory stimulating drugs and obstructive sleep apnoea/ hypopnoea syndrome. Six patients were withdrawn because of an exacerbation during the study. The remaining 17 patients received optimal medication, consisting of bronchodilators and in some cases loop diuretics and inhaled corticosteroids. The medication remained unchanged during the study period.

\section{Study protocol}

In a double-blind, double-dummy, randomised study the effects of a 2-week treatment of ACET (250 mg b.i.d.) or MPA (30 mg b.i.d.), followed by a combination of MPA/ACET on daytime and nocturnal ventilatory and blood gas parameters were studied. The study design is shown in figure 1 . The patients were studied four times over a period of 6 weeks: at the beginning of the study and before a change of medication; after introduction of the placebo and single or combined drug treatment, at intervals of 2 weeks (study points T1-4, fig. 1). The measurements consisted of nocturnal measurements followed by daytime tests. All patients received a placebo during the first 2 weeks to determine the intraindividual variability in the outcome parameters. After the second measurements (T2) patients received either MPA (30 mg)+placebo (arm 1) or ACET (250 mg)+placebo (arm 2) twice daily (b.i.d.). Over the final study period all patients received combined treatment with MPA (30 mg b.i.d.) and ACET (250 mg b.i.d.), all in identical capsules.

At 1 and 3 months after the end of the last

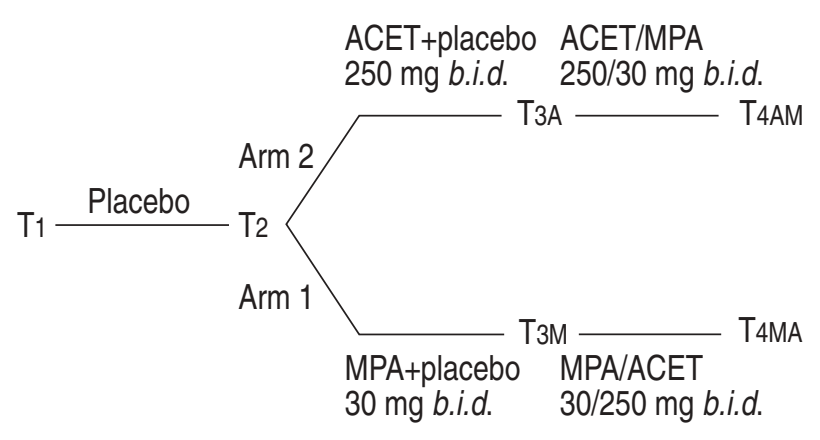

\begin{tabular}{lllll}
\hline 0 & 1 & 4 & 6
\end{tabular}

Fig. 1.-Study design. MPA: medroxyprogesterone acetate; ACET: acetazolamide; T1: baseline measurements; T2: measurements after 2 weeks placebo; T3A: measurements after 2 weeks ACET+placebo; T3M: measurements after 2 weeks MPA+placebo; T4AM: measurements after 2 weeks ACET+placebo followed by 2-week treatment with ACET and MPA; T4MA: measurements after 2 weeks MPA+placebo followed by 2-week treatment with and MPA and ACET.

treatment, hypercapnic ventilatory response and arterial blood gas values were measured in nine and seven patients, respectively, to observe possible sustained effects after MPA/ACET. Written informed consent was obtained from all patients and the study was approved by the Hospital Ethics Committee.

\section{Daytime measurements}

All daytime measurements were performed on the morning after the nocturnal measurement.

Arterial blood gas values. After each study night at 09:00 h an arterial blood sample was taken after 15 min of rest (Ciba-Corning 278 blood gas analyser; Ciba-Corning, Houten, the Netherlands).

Pulmonary function tests. Spirometric tests, including inspiratory vital capacity, total lung capacity, residual volume and forced expiratory volume in one second were performed with a wet spirometer and helium (He) dilution technique (Pulmonet III; SensorMedics, Anaheim, CA, USA). Reference values were derived from ERS standards [19].

Pressure measurements. Maximal inspiratory and expiratory mouth pressure $(P \mathrm{I}, \max$ and $P \mathrm{E}, \mathrm{max})$ were measured as described by Wilson et al. [20].

Hypercapnic ventilatory response and hypoxic ventilatory response. The hypercapnic ventilatory response (HCVR) was assessed by the steady-state method [21]. The patient was connected to a closed spirometric circuit (Pulmotest; Godart, Bilthoven, the Netherlands) via a mouthpiece. A Rudolph valve 2700 (Hans Rudolph, Kansas City, USA) was placed in the system to maintain a one-way circuit. The end-tidal $\mathrm{CO}_{2}$ tension $\left(P \mathrm{ET}, \mathrm{CO}_{2}\right)$ level was measured by a sidestream capnograph (Dräger, Lübeck, Germany). 
Inspiratory $\mathrm{CO}_{2}$ pressure $\left(\mathrm{PI}_{1}, \mathrm{CO}_{2}\right)$ could be raised by adjusting a three-way valve, partly short-circuiting the $\mathrm{CO}_{2}$ absorber in the inspiratory limb of the circuit. Two different levels of $P \mathrm{ET}, \mathrm{CO}_{2}$ were determined $\left(P \mathrm{ET}, \mathrm{CO}_{2}\right.$ at zero $P \mathrm{I}, \mathrm{CO}_{2}$, and $P \mathrm{ET}, \mathrm{CO}_{2}$ at $1-1.5 \mathrm{kPa}$ above resting value) and the slope (minute ventilation $\left.\left(V^{\prime} \mathrm{E}\right) / P \mathrm{ET}, \mathrm{CO}_{2}\right)$ and $\mathrm{x}$-intercept $\mathrm{B}$ were calculated, according to the equation of the steady state relation of ventilation and $P$ ET, $\mathrm{CO}_{2}$ at constant end-tidal $\mathrm{O}_{2}$ concentration:

$$
V^{\prime} \mathrm{E}=S\left(P \mathrm{ET}, \mathrm{CO}_{2}-\mathrm{B}\right)
$$

Each level of $P$ ET, $\mathrm{CO}_{2}$ was maintained for at least $7 \mathrm{~min} . \mathrm{O}_{2}$ was added to the system to keep arterial $\mathrm{O}_{2}$ saturation $\left(\mathrm{Sa}_{\mathrm{a}} \mathrm{O}_{2}\right)$ constant at levels $>90 \%$. $\mathrm{Sa}, \mathrm{O}_{2}$ was measured with an pulse oximeter (Oxyshuttle; SensorMedics, Anaheim, CA, USA). At the end of the steady-state period of the HCVR an arterialised capillary blood sample was taken. Mouth occlusion pressure $\left(P_{0.1}\right)$ was measured during the final 2 min of each steady-state period at the two different levels of $P \mathrm{I}, \mathrm{CO}_{2}$ using a solenoid valve, in the inspiratory part of the circuit.

The hypoxic ventilatory response (HVR) was performed by inducing progressive isocapnic hypoxia. $P$ ET, $\mathrm{CO}_{2}$ was maintained at the pre-drug level $\left(\mathrm{T}_{2}\right.$, placebo treatment) during all HVR tests, by adding $\mathrm{CO}_{2}$ to the inspirate when necessary. All patients started the test at normoxia $\left(\mathrm{Sa}_{\mathrm{a}, \mathrm{O}_{2}}\right.$ level of $\left.>95 \%\right)$, by adding an adequate amount of $\mathrm{O}_{2}$. Next, inspiratory $\mathrm{O}_{2}$ was decreased by stopping the $\mathrm{O}_{2}$ supplementation and the HVR test was performed until $\mathrm{Sa}_{\mathrm{a}} \mathrm{O}_{2}$ reached $80 \%$.

During the recording of both the HCVR and HVR, the $P$ ET, $\mathrm{CO}_{2}$, breathing frequency, tidal volume, $V^{\prime} \mathrm{E}$, $\mathrm{Sa}_{\mathrm{a}, \mathrm{O}_{2}}$ and $P 0.1$ were measured and stored on an analogue chart recorder (BD101; Kipp \& Zonen, Delft, the Netherlands).

\section{Nocturnal measurements}

The $\mathrm{Sa}_{\mathrm{a}} \mathrm{O}_{2}$ was measured by a pulse oximeter. The baseline $\mathrm{Sa}_{\mathrm{a}} \mathrm{O}_{2}$ awake was defined as the mean $\mathrm{Sa}_{\mathrm{a}} \mathrm{O}_{2}$ during the first $15 \mathrm{~min}$ of the recording, when the patient was awake and in the supine position. The $P$ ET, $\mathrm{CO}_{2}$ was measured by sampling air through a naso-pharyngeal cannula inserted via the nose and connected to the sampling capnograph (Mijnhart capnolyser; Mijnhart, Bilthoven, the Netherlands). $\mathrm{O}_{2}$ saturation, and $P$ ET, $\mathrm{CO}_{2}$ signals during the night were stored on a computer (Compaq 4/66; Compaq, Houston, TX, USA).

\section{Subjective parameters}

After each study period patients were asked about the side-effects of the drugs. The dyspnoea sensation was analysed with the modified Medical Research Council (MRC) scale [22].

\section{Statistical analysis}

In this study, four repeated measurements were made, at the beginning and at the end of each period (T1-4). Data are presented as mean \pm SEM. In order to test whether the effect of the combined treatment was different in both arms of the study (arm effects), the differences (T1-4AM-T2, arm 2) and (T1-4MA-T2, arm 1) were compared using the Mann Whitney U test. After showing that there was no significant intraindividual variability, by comparing $\mathrm{T} 1$ and $\mathrm{T} 2$, and that there were no arm effects at $\mathrm{T} 4$, the data obtained in the placebo situation were compared with those after combined treatment with MPA/ACET. Combination therapy was compared with single drug treatment (Wilcoxon signed-rank tests). A Bonferoni correction was used because of multiple comparisons, a $p<0.025$ was considered statistically significant.

\section{Results}

The anthropometric characteristics, baseline respiratory function data, acid-base status and nocturnal parameters of the patients in both arms are summarised in table 1. After placebo, no significant differences were observed in ventilatory and blood gas parameters or in nocturnal measurements compared to baseline $\left(\mathrm{T}_{2}-\mathrm{T} 1\right)$. Hence, there was no significant intra-individual variability, and the data of the placebo measurements were used as reference values in the analysis of the effects of ACET, MPA and the combined drug treatment. No arm effects

Table 1.-Baseline characteristics ( $\left.\mathrm{T}_{1}\right)$

\begin{tabular}{|c|c|c|}
\hline & Arm $1^{\#}$ & $\operatorname{Arm} 2^{\bullet}$ \\
\hline Age yrs & $66+2$ & $69+2$ \\
\hline Weight $\mathrm{kg}$ & $83+8$ & $70+5$ \\
\hline Height $\mathrm{m}$ & $1.72 \pm 0.04$ & $1.65 \pm 0.03$ \\
\hline Body mass index $\mathrm{kg} \cdot \mathrm{m}^{-2}$ & $28 \pm 2$ & $26 \pm 2$ \\
\hline FEV $1 \%$ pred & $37 \pm 6$ & $30 \pm 4$ \\
\hline $\mathrm{FEV} 1 / \mathrm{VC} \%$ pred & $46+7$ & $48+6$ \\
\hline TLC $\%$ pred & $100 \pm 6$ & $92 \pm 7$ \\
\hline IVC $\%$ pred & $80 \pm 4$ & $68 \pm 1$ \\
\hline RV \% pred & $145 \pm 20$ & $137 \pm 10$ \\
\hline $\mathrm{pH}$ & $7.39 \pm 0.01$ & $7.41 \pm 0.01$ \\
\hline$P \mathrm{a}_{1} \mathrm{O}_{2} \mathrm{kPa}$ & $8.2+0.4$ & $8.4+0.5$ \\
\hline$P \mathrm{a}, \mathrm{CO}_{2} \mathrm{kPa}$ & $6.6 \pm 0.1$ & $6.3 \pm 0.2$ \\
\hline $\mathrm{BE} \mathrm{mEq} \cdot \mathrm{L}^{-1}$ & $4.3 \pm 1.0$ & $4.6 \pm 0.9$ \\
\hline $\mathrm{Sa}_{\mathrm{a}, \mathrm{O}_{2}} \%$ & $90.0 \pm 1.0$ & $91.1 \pm 1.6$ \\
\hline \multicolumn{3}{|l|}{ Nocturnal parameters } \\
\hline Mean $\mathrm{Sa}_{\mathrm{a}} \mathrm{O}_{2} \%$ & $84.8 \pm 2.0$ & $86.7 \pm 2.6$ \\
\hline Time $S_{\mathrm{a}, \mathrm{O}_{2}}<90 \% \%$ & $72.2 \pm 12.8$ & $48.9 \pm 15.3$ \\
\hline Lowest $S_{\mathrm{a}, \mathrm{O}_{2}} \%$ & $70.5+3.2$ & $72.1+4.2$ \\
\hline Mean $P$ ET, $\mathrm{CO}_{2} \mathrm{kPa}$ & $6.1 \pm 0.3$ & $5.0 \pm 0.3$ \\
\hline
\end{tabular}

Data are presented as mean \pm SEM. FEV1: forced expiratory volume in one second; VC: vital capacity; TLC: total lung capacity; IVC: inspiratory vital capacity; RV: residual volume; $P \mathrm{a}_{2} \mathrm{O}_{2}$ : oxygen tension in arterial blood; $P \mathrm{a}_{1}, \mathrm{CO}_{2}$ : carbon dioxide tension in arterial blood; BE: base excess; $\mathrm{Sa}_{\mathrm{a}} \mathrm{O}_{2}$ : arterial oxygen saturation; $P \mathrm{ET}, \mathrm{CO}_{2}$ : end-tidal carbon dioxide tension. ${ }^{\#}: \mathrm{n}=9 ;{ }^{\natural}: \mathrm{n}=8$. 
Table 2. - Analysis of arm effects

\begin{tabular}{lrrr}
\hline Parameter & T1-4AM-T2 & T1-4MA-T2 & p-value \\
\hline$P \mathrm{a}, \mathrm{CO}_{2} \mathrm{kPa}$ & $-1.0 \pm 0.2$ & $-1.4 \pm 0.2$ & 0.09 \\
$P \mathrm{a}, \mathrm{O}_{2} \mathrm{kPa}$ & $1.4 \pm 0.2$ & $2.2 \pm 0.4$ & 0.06 \\
$V^{\prime} \mathrm{E} \mathrm{L} \cdot \mathrm{min}^{-1}$ & $0.5 \pm 0.3$ & $0.6 \pm 0.4$ & 0.82 \\
$P 0.1 \mathrm{kPa}$ & $0.3 \pm 0.1$ & $-0.2 \pm 0.1$ & 0.41 \\
\hline
\end{tabular}

Data are presented as mean \pm SEM. $P$ a, $\mathrm{CO}_{2}$ : carbon dioxide tension in arterial blood; $\mathrm{Pa}_{\mathrm{a}} \mathrm{O}_{2}$ : oxygen tension in arterial blood; $V^{\prime}$ E: minute ventilation; $P 0.1$ : mouth occlusion pressure.

were found with MPA/ACET (table 2), therefore, the data of the combined treatment of both arms were analysed as one group. Furthermore, placebo versus single treatments with either MPA $(n=8)$ or ACET $(n=9)$ were compared to placebo versus combined treatment with MPA/ACET $(n=17)$ and combined treatment was compared to single treatment.

\section{Daytime blood gas parameters}

Single treatment. Compared to the placebo, as shown in table 3, ACET significantly decreased $\mathrm{Pa}_{2} \mathrm{CO}_{2}, \mathrm{pH}$ and base excess (BE) and improved $\mathrm{Pa}_{2} \mathrm{O}_{2}$ and $\mathrm{Sa}_{2} \mathrm{O}_{2}$ values. MPA increased $P \mathrm{a}, \mathrm{O}_{2}$ and $\mathrm{Sa}_{\mathrm{a}} \mathrm{O}_{2}$ and decreased $\mathrm{Pa}, \mathrm{CO}_{2}$ and $\mathrm{BE}$.

Combined treatment. During combined treatment, patients became normocapnic and almost normoxic compared to the placebo treatment (table 3).

Analysis of differences between combined and single treatment resulted in a significant difference in $\mathrm{pH}$ (combined versus MPA), $\mathrm{Pa}_{\mathrm{a}} \mathrm{O}_{2}$ and $\mathrm{BE}$ (combined versus both single drug treatments) and $\mathrm{Pa}_{\mathrm{a}} \mathrm{CO}_{2}$ (combined versus ACET) (table 3).

\section{Ventilatory parameters}

The main results of the ventilatory data including HCVR and HVR are shown in table 4. Ventilation did not increase after single treatment but did increase significantly after combined therapy, compared to placebo.

The slope of the ventilatory $\mathrm{CO}_{2}$ response curve significantly increased with combination therapy when compared to placebo (fig. 2). The slope of the HVR:

$$
S_{\mathrm{H}, \mathrm{VR}}=V^{\prime} \mathrm{E} / S_{\mathrm{a}, \mathrm{O}_{2}}
$$

and the $P_{0.1}$ response to hypoxia, expressed as function of $S \mathrm{a}, \mathrm{O}_{2}$ :

$$
S_{\mathrm{H}, P 0.1}=P_{0.1} / S_{\mathrm{a}, \mathrm{O}_{2}}
$$

increased with combined treatment, both compared to placebo. No significant changes were found with the single drug therapy. $S \mathrm{H}, P 0.1$ expressed as function of $V^{\prime} \mathrm{E}$ resulted in a correlation coefficient of $\mathrm{r}=0.98$.

A significant increase in $P$ I, max was found with combination therapy compared to placebo.

\section{Nocturnal measurements}

Single treatment. As shown in table 3, the lowest nocturnal $S \mathrm{a}_{2} \mathrm{O}_{2}$ increased significantly with single drug therapies.

Combined treatment. When comparing the combined treatment with the single drug and the placebo treatments, there was a significant decrease in $P$ ET, $\mathrm{CO}_{2}$ and a significant improvement in $\mathrm{Sa}_{2} \mathrm{O}_{2}$ values. When comparing only the placebo with the combined treatment, the lowest $\mathrm{Sa}_{2} \mathrm{O}_{2}$ values were improved and the percentage of time $S_{\mathrm{a}}, \mathrm{O}_{2}<90 \%$ was significantly reduced (table 3 ).

\section{Subjective parameters}

Single treatment. During single MPA therapy four patients reported gastro-intestinal discomfort and four patients fatigue. No complaints of impotence, decreased libido, gynecomasty or other feminine characteristics in the male population were reported. In the single ACET group two patients complained of

Table 3. -Effect of placebo, medroxyprogesterone (MPA), acetazolamide (ACET) and combined drug therapy (MPA

\begin{tabular}{|c|c|c|c|c|}
\hline & Placebo $^{\#}$ (T2) & $\operatorname{ACET}^{*}(\mathrm{~T} 3 \mathrm{~A})$ & $\mathrm{MPA}^{+}(\mathrm{T} 3 \mathrm{M})$ & MPA/ACET ${ }^{\#}$ (T4) \\
\hline $\mathrm{pH}$ & $7.39 \pm 0.01$ & $7.34 \pm 0.01^{\S}$ & $7.40 \pm 0.01^{\S}$ & $7.36 \pm 0.01^{\S, \# \#}$ \\
\hline$P a, O_{2} \mathrm{kPa}$ & $7.9 \pm 0.3$ & $8.5 \pm 0.2^{\S}$ & $8.9 \pm 0.6^{\S}$ & $9.6 \pm 0.4^{\S, f, \# \#}$ \\
\hline $\mathrm{Pa}, \mathrm{CO}_{2} \mathrm{kPa}$ & $6.5 \pm 0.2$ & $6.1 \pm 0.2^{\S}$ & $5.8 \pm 0.3^{\S}$ & $5.3 \pm 0.2^{\S, f}$ \\
\hline $\mathrm{BE} \mathrm{mEq} \cdot \mathrm{L}^{-1}$ & $4.5 \pm 0.7$ & $0.8 \pm 1.3^{\S}$ & $2.6 \pm 1.0^{\S}$ & $-2.4 \pm 0.8^{\S, f, \# \#}$ \\
\hline$P(\mathrm{a}-\mathrm{ET}), \mathrm{CO}_{2} \mathrm{kPa}$ & $0.7 \pm 0.2$ & $0.6 \pm 0.2$ & $0.7 \pm 0.2$ & $0.7 \pm 0.2$ \\
\hline $\mathrm{Sa}_{\mathrm{a}} \mathrm{O}_{2} \%$ & $89.0 \pm 1.3$ & $90.6 \pm 0.8^{\S}$ & $92.0 \pm 1.7^{\S}$ & $92.3 \pm 1.0^{\S}$ \\
\hline \multicolumn{5}{|l|}{ Nocturnal parameters } \\
\hline Mean $P \mathrm{ET}, \mathrm{CO}_{2} \mathrm{kPa}$ & $5.5 \pm 0.2$ & $5.2 \pm 0.3$ & $4.6 \pm 0.3$ & $4.1 \pm 0.2^{\S, f, \# \#}$ \\
\hline Mean $\mathrm{S}_{\mathrm{a}, \mathrm{O}_{2}} \%$ & $85.5 \pm 1.6$ & $87.2 \pm 1.3$ & $88.6 \pm 2.3$ & $90.2 \pm 1.0^{\S, f, \# \#}$ \\
\hline Lowest $S_{\mathrm{a}, \mathrm{O}_{2}} \%$ & $70.9 \pm 2.9$ & $74.9 \pm 3.1^{\S}$ & $80.1 \pm 3.3$ & $78.6 \pm 1.8^{\S}$ \\
\hline Time $\mathrm{S}_{\mathrm{a}, \mathrm{O}_{2}}<90 \% \%$ & $61.8 \pm 9.9$ & $63.4 \pm 13.4$ & $46.8 \pm 16.7$ & $42.0 \pm 10.4^{\S}$ \\
\hline
\end{tabular}
ACET) on daytime and nocturnal parameters

Data are presented as mean \pm SEM. $P$ a, $\mathrm{O}_{2}$ : oxygen tension in arterial blood; $P$ a, $\mathrm{CO}_{2}$ : carbon dioxide tension in arterial blood; $\mathrm{BE}$ : base excess; $P(\mathrm{a}-\mathrm{ET}), \mathrm{CO}_{2}$ : arterial-to-end tidal carbon dioxide tension gradient; $S_{\mathrm{a}, \mathrm{O}_{2}}$ : arterial oxygen saturation; $P$ ET,CO ${ }_{2}$ : end-tidal carbon dioxide tension. ${ }^{\#}: \mathrm{n}=17 ;{ }^{\uparrow}: \mathrm{n}=9 ;{ }^{+}: \mathrm{n}=8 ;{ }^{\S}: \mathrm{p}<0.025$ any treatment versus placebo; ${ }^{f}: \mathrm{p}<0.025$ combined treatment versus ACET; ${ }^{\# \#}: \mathrm{p}<0.025$ combined treatment versus MPA. 
Table 4. - Effect of placebo, medroxyprogesterone acetate (MPA), acetazolamide (ACET) and combined drug therapy (MPAACET) on ventilatory parameters and respiratory muscle strength

\begin{tabular}{|c|c|c|c|c|}
\hline & Placebo $^{\#}$ (T2) & $\operatorname{ACET}^{\top}(\mathrm{T} 3 \mathrm{~A})$ & $\mathrm{MPA}^{+}(\mathrm{T} 3 \mathrm{M})$ & MPA/ACET ${ }^{\#}$ (T4) \\
\hline$V^{\prime} \mathrm{E} \mathrm{L} \cdot \mathrm{min}^{-1}$ & $9.3 \pm 0.5$ & $9.5 \pm 0.9$ & $10.2 \pm 0.6$ & $11.2 \pm 0.8^{\S, f}$ \\
\hline$V \mathrm{~T} L$ & $0.6 \pm 0.06$ & $0.8 \pm 0.2$ & $0.6 \pm 0.04$ & $0.7 \pm 0.1^{\S}$ \\
\hline$P 0.1$ at rest $\mathrm{kPa}$ & $0.5 \pm 0.04$ & $0.5 \pm 0.03$ & $0.6 \pm 0.05$ & $0.5 \pm 0.04$ \\
\hline$S$ HCVR L $\cdot \min ^{-1} \cdot \mathrm{kPa}^{-1}$ & $3.7 \pm 0.6$ & $5.5 \pm 1.4$ & $4.8 \pm 1.4$ & $5.8 \pm 1.0^{\S}$ \\
\hline BHCVR kPa & $2.9 \pm 0.5$ & $3.6 \pm 0.4$ & $2.8 \pm 0.5$ & $2.9 \pm 0.3$ \\
\hline 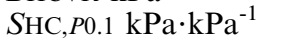 & $0.3 \pm 0.04$ & $0.2 \pm 0.04$ & $0.4 \pm 0.08$ & $0.4 \pm 0.04$ \\
\hline$B \mathrm{HC}, P 0.1 \mathrm{kPa}$ & $4.2 \pm 0.3$ & $3.7 \pm 0.3$ & $3.6 \pm 0.4$ & $2.9 \pm 0.3$ \\
\hline$S_{\text {HVR }} \mathrm{L} \cdot \mathrm{min}^{-1} / \%$ & $-0.13 \pm 0.03$ & $-0.20 \pm 0.05$ & $-0.40 \pm 0.11$ & $-0.40 \pm 0.07^{\S}$ \\
\hline$S \mathrm{H}, P 0.1 \mathrm{kPa} / \%$ & $-0.01 \pm 0.0$ & $-0.01 \pm 0.0$ & $-0.02 \pm 0.01$ & $-0.03 \pm 0.01^{\S}$ \\
\hline$P \mathrm{I}, \max \mathrm{kPa}$ & $5.7 \pm 0.5$ & $6.3 \pm 0.8$ & $5.4 \pm 0.5$ & $6.7 \pm 0.7^{\S}$ \\
\hline$P$ E,max $\mathrm{kPa}$ & $9.3 \pm 0.7$ & $10.0 \pm 1.1$ & $8.6 \pm 0.8$ & $9.6 \pm 0.7$ \\
\hline
\end{tabular}

Data are presented as mean \pm SEM. $V^{\prime}$ E: minute ventilation; $V$ T: tidal volume; $P 0.1$ at rest: mouth occlusion pressure at rest; SHCVR: slope of the ventilatory carbon dioxide $\left(\mathrm{CO}_{2}\right)$ response curve $\left(V^{\prime} \mathrm{E} /\right.$ carbon dioxide tension in arterial blood $\left.\left(P \mathrm{a}, \mathrm{CO}_{2}\right)\right)$; $B$ HCVR: apnoeic threshold or extrapolated end-tidal $\mathrm{CO}_{2}$ tension at zero ventilation (x-intercept); $S \mathrm{HC}, P 0.1$ : slope of the mouth occlusion response to $\mathrm{CO}_{2}\left(P_{0.1} / P_{\mathrm{a}}, \mathrm{CO}_{2}\right) ; B \mathrm{HC}, P 0.1$ : x-intercept of the mouth occlusion pressure response to $\mathrm{CO}_{2} ; S \mathrm{HVR}$ : slope of the hypoxic ventilatory response ( $V^{\prime}$ E/arterial oxygen saturation $\left.\left(S_{\mathrm{a}}, \mathrm{O}_{2}\right)\right) ; S \mathrm{H}, P 0.1$ : slope of the mouth occlusion response to hypoxia $\left(P 0.1 / S_{\mathrm{a}, \mathrm{O}_{2}}\right)$; PI,max: inspiratory mouth occlusion pressure; $P \mathrm{E}$,max: expiratory mouth occlusion pressure. ${ }^{\#}: \mathrm{n}=17$; : $\mathrm{n}=9 ;{ }^{+}: \mathrm{n}=8 ;{ }^{\S}: \mathrm{p}<0.025$ any treatment versus placebo; ${ }^{f}: \mathrm{p}<0.025$ combined treatment versus ACET.

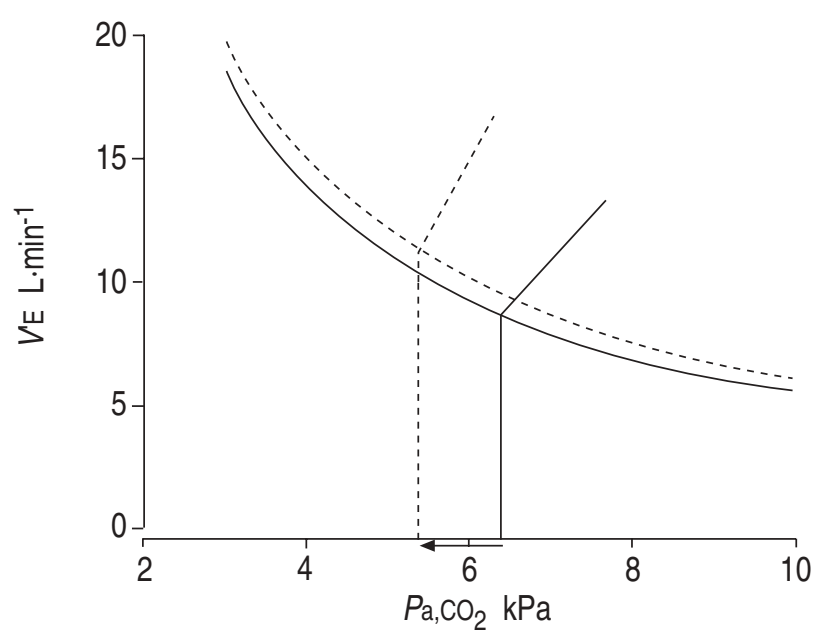

Fig. 2. - Effect of placebo (-) or combined therapy with medroxyprogesterone acetate (MPA) and acetazolamide (ACET) (----) on ventilatory control system. The metabolic hyperbola with placebo (-, straight line) and combination therapy (---, straight line) are shown. $V^{\prime} \mathrm{E}$ : minute ventilation; $P \mathrm{a}, \mathrm{CO}_{2}$ : carbon dioxide tension in arterial blood.

gastro-intestinal discomfort, one patient of headaches and three patients complained of fatigue.

Dyspnoea sensation (MRC scale) remained unchanged: $2.06 \pm 0.18$ at placebo, $2.00 \pm 0.33$ with ACET therapy and $2.88 \pm 0.23$ during MPA therapy.

Combined therapy. During combined treatment gastro-intestinal complaints $(n=3)$, headache $(n=1)$, fatigue $(n=3)$ and paraesthesia $(n=6)$ were reported. No complaints of impotence, decreased libido, gynecomasty or other feminine characteristics in the male population were reported. The dyspnoea score did not change significantly $(2.47 \pm 0.19)$.

\section{Off-treatment}

At 1 month and 3 months after discontinuing the combined treatment, no significant differences were found between placebo and the off-treatment data (table 5).

\section{Discussion}

The present study showed that in hypercapnic patients with COPD, combination therapy with MPA/ACET normalised daytime blood gas values and improved night-time and ventilatory parameters. The improvement was greater with the combined drug treatment than with either of the single drug treatments.

\section{Daytime blood gas parameters}

ACET and MPA given as single drugs, decreased the daytime $\mathrm{Pa}_{2} \mathrm{CO}_{2}(0.4 \mathrm{kPa}(6 \%)$ and $0.7 \mathrm{kPa}(11 \%)$, respectively) and increased $\mathrm{Pa}_{\mathrm{a}} \mathrm{O}_{2}(0.6 \mathrm{kPa}(9 \%)$ and $1.0 \mathrm{kPa}(13 \%)$, respectively). The effect of combined treatment was additive; $\mathrm{Pa}_{1} \mathrm{CO}_{2}$ decreased $1.2 \mathrm{kPa}$

Table 5. - Off-treatment effects

\begin{tabular}{|c|c|c|c|}
\hline Parameter & Placebo & AI-1 month ${ }^{\#}$ & AI-3 months \\
\hline$P a, \mathrm{O}_{2} \mathrm{kPa}$ & $7.9 \pm 0.3$ & $9.0 \pm 0.4$ & $7.8 \pm 0.5$ \\
\hline$P \mathrm{a}, \mathrm{CO}_{2} \mathrm{kPa}$ & $6.5 \pm 0.2$ & $5.9 \pm 0.1$ & $6.6 \pm 0.4$ \\
\hline$V^{\prime} \mathrm{E} \mathrm{L} \cdot \min ^{-1}$ & $9.3 \pm 0.5$ & $9.3 \pm 1.4$ & $11 . \overline{2 \pm 1.7}$ \\
\hline$S_{\text {HCVR L }} \cdot \mathrm{min}^{-1} \cdot \mathrm{kPa}^{-1}$ & $3.7 \pm 0.6$ & $6.7 \pm 1.6$ & $4.1 \pm 1.9$ \\
\hline
\end{tabular}

Data are presented as mean \pm SEM. AI: after interruption of acetazolamide and medroxyprogesterone acetate treatment; $\mathrm{P}_{\mathrm{a}, \mathrm{O}_{2}}$ : oxygen tension in arterial blood; $\mathrm{Pa}_{\mathrm{a}} \mathrm{CO}_{2}$ : carbon dioxide tension in arterial blood; $V^{\prime} \mathrm{E}$ : minute ventilation; SHCVR: slope of the ventilatory $\mathrm{CO}_{2}$ response curve $\left(V^{\prime} \mathrm{E} / P \mathrm{a}, \mathrm{CO}_{2}\right) ;{ }^{\#}: \mathrm{n}=9 ;{ }^{\oplus}: \mathrm{n}=7$. 
$(19 \%)$ and $\mathrm{Pa}, \mathrm{O}_{2}$ increased $1.7 \mathrm{kPa}(23 \%)$, reaching normocapnic and almost normoxic values. The findings on monotherapy are not new and in agreement with the literature $[7,14,23,24]$. Conversely, the results of combination therapy have not been shown before. The improvement observed with combination therapy may be due to the significant increase in $V^{\prime} \mathrm{E}$ $\left(1.9 \mathrm{~L} \cdot \mathrm{min}^{-1}\right)$, which was more than the sum of the slight increases seen with single MPA and ACET treatment.

\section{Hypercapnic ventilatory response}

The slope of the HCVR increased significantly with MPA/ACET therapy, whereas with the single drug treatment no significant change was observed. The latter agrees with existing data [14], although an increase in HCVR on monotherapy has been found by others [7, 23]. The fact that the effects on HCVR and on the blood gas parameters with combined treatment with MPA/ACET were slightly better than with single drug treatment suggests that combination therapy was additive. This also suggests that there is no interaction between the ventilatory drive from the chemoreceptors and the drive mediated by the hypothalamus.

The ventilatory control system, as shown in figure 2, consists of two parts: 1) the linear ventilatory response to $\mathrm{CO}_{2}$, which represents the controller or controlling system with $\mathrm{Pa}, \mathrm{CO}_{2}$ as input parameter and $V^{\prime} \mathrm{E}$ as output parameter; and 2) the metabolic hyperbola which represents the controlled system and depends on the metabolic $\mathrm{CO}_{2}$ production. The controlled system comprises of the gas exchanging process in the lungs, with $V^{\prime} \mathrm{E}$ as the input parameter and $P \mathrm{a}, \mathrm{CO}_{2}$ as the output parameter. In a spontaneously breathing male, in the so-called "closed loop" situation, the working-point is represented by the intersection of both curves: the output of the controlled system $\left(\mathrm{Pa}_{\mathrm{a}} \mathrm{CO}_{2}\right)$ is the input of the controller and the output of the controller $\left(V^{\prime} \mathrm{E}\right)$ is the input of the controlled system. In the current model, a resting $\mathrm{CO}_{2}$ production of $400 \mathrm{~mL} \cdot \mathrm{min}^{-1}$ was calculated, which increased during MPA to $450 \mathrm{~mL} \cdot \mathrm{min}^{-1}$, based on the actual $V^{\prime} \mathrm{E}$ and $P \mathrm{a}, \mathrm{CO}_{2}$ values of the patient groups.

It is important to recognise whether chronic hypercapnia is due to neuromuscular weakness, the excessive work of breathing ("can't breathe") or due to inadequate drive from the ventilatory centres in the central nervous system ("won't breathe"). According to the metabolic hyperbola, a substantial decrease in $P \mathrm{a}, \mathrm{CO}_{2}$ of $1.2 \mathrm{kPa}$ can be generated by a very small increase in ventilation of $1.9 \mathrm{~L} \cdot \mathrm{min}^{-1}$ during chronic hypercapnia. Therefore, respiratory stimulants like ACET and MPA can be considered for hypercapnic patients with severe COPD, as also discussed by TEPPEMA and DAHAN [25], because they are able to improve blood gas values considerably with only minimal changes in ventilation and without an increase in dyspnoea sensation. Dyspnoea sensation was measured by the rather insensitive MRC scale and it is conceivable that a more sensitive scale for dyspnoea might have revealed differences between the various therapeutic regimens.

\section{Hypoxic ventilatory response}

In this study, it was found that the HVR was not augmented by single drug treatment, whereas combination therapy increased HVR. In the current literature, the effects of MPA and ACET on the HVR are confounded by the fact that the same preand post-drug levels of $P \mathrm{ET}, \mathrm{CO}_{2}$ were not always maintained $[7,26]$. $\mathrm{HVR}$ is not only determined by $\mathrm{O}_{2}$ pressure but also by the prevailing $P \mathrm{I}, \mathrm{CO}_{2}$. This is well illustrated by the study of ToJima et al. [26], who showed that the effect on HVR measured during ACET-induced hypocapnia did not significantly increase, whereas responses to hypoxia measured under pre-drug $P$ ET, $\mathrm{CO}_{2}$ levels did increase significantly.

Vos et al. [7] showed no significant increase in HVR with chlormadinone acetate, which was measured at hypocapnic post-drug level. In this study, pre-drug $P$ ET, $\mathrm{CO}_{2}$ levels were used. Both ACET and MPA probably have an effect on the peripheral chemoreceptors, whereas progesterone induces an increase in metabolic rate, which in turn may be responsible for the increase in HVR [27]. The lower BE (metabolic acidosis) will also contribute to the increased HVR during the combined treatment.

Whitelaw and Derenne [28] introduced the mouth occlusion pressure $\left(P_{0.1}\right)$ measurement as an output parameter of the controlling part of the respiratory control system, because in COPD patients ventilation as an output parameter can be influenced by chronic airway obstruction. $P 0.1$ is a measure of neuromuscular drive, minimising the influences of airway obstruction. The $P 0.1$ values at rest, measured in the COPD patients in the present study, were comparable with those described in other studies [14, 28].

The $P 0.1 / \mathrm{Sa}_{\mathrm{a}} \mathrm{O}_{2}$ response slope was augmented by combination therapy, whereas single drug treatment only caused a slight nonsignificant increase. In the COPD patients in this study the measurement of $P 0.1$ as an output parameter of the respiratory controlling system was comparable to $V^{\prime} \mathrm{E}$, as is shown by the high correlation coefficient.

The combination of MPA and ACET showed a significant increase in inspiratory mouth pressure. A possible mechanism could be an increase in central and voluntary drive, although this could not be confirmed with the scarce data in the literature [29]. Single drug treatment did not improve respiratory muscle function and this has also been shown for MPA by Contreras et al. [30].

\section{Subjective parameters}

Gastro-intestinal complaints, as well as fatigue and headaches, have been described using both drugs. Side-effects in males using female hormones have also been described. Since a low dose was used in this study, and as the treatment was short term, none of these side-effects were expected. Only studies with high doses of MPA (up to 1,000 mg daily) have been shown to induce side-effects. As only a low dose (60 mg daily) of MPA was used in this study no direct comparison can be made. If low doses of MPA are to 
be used in hypercapnic COPD patients, a long-term study has to be performed in order to gain further insights into the side-effects of female hormonal treatment in males.

The MRC dyspnoea scale did not significantly change with either single drug or combined drug treatment. There are no studies published in which dyspnoea or a quality of life score have been used to assess treatment with respiratory stimulants in hypercapnic COPD patients. The present study is unable draw any conclusion on this topic. Long-term therapy with the combined drug treatment will provide a greater insight into the dyspnoea sensation and quality of life in the future.

\section{Nocturnal measurements}

In COPD patients, MPA and ACET are proven to have a beneficial effect on central sleep apnoea and oxygenation $[8,9,13,17]$. In the present study, an improvement in mean nocturnal $P$ ET, $\mathrm{CO}_{2}, S_{\mathrm{a}} \mathrm{O}_{2}$ and lowest $\mathrm{Sa}_{\mathrm{a}} \mathrm{O}_{2}$, and a decrease of the percentage of time $S \mathrm{a}, \mathrm{O}_{2}<90 \%$ was found. The maximal dose of ACET shown not to induce a significant arterial-to-end tidal $\mathrm{CO}_{2}$ tension gradient gradient was $4 \mathrm{mg} \cdot \mathrm{kg}^{-1}$ in cats (which is equivalent to $250 \mathrm{mg}$ ACET every 8-12 h) [31]. SwENSON [31] also showed that although a higher dose may increase ventilation, an impaired $\mathrm{CO}_{2}$ transport and ventilation/perfusion mismatch in the lung occurs. Furthermore, in the treatment of central apnoea syndrome as well as obstructive sleep apnoea, a low dose of ACET $\left(250 \mathrm{mg} \cdot \mathrm{day}^{-1}\right)$ was shown to be sufficient to increase overall tonic output of the respiratory controller, augment breathing and to improve quality of life. However, in the latter patient group no decrease was observed in peripheral chemosensitivity in contrast to COPD patients and this might be an explanation for the difference in drug regimen. It remains to be established, however, whether isolated nocturnal desaturation needs to be treated at all [32]. One month after discontinuation of the combined treatment with MPA and ACET, all parameters which were found to have changed significantly had returned to baseline values. Six months after cessation of ACET, VerbraecKen et al. [17] showed that the number of central apnoeas was still reduced in five out of eight patients with central sleep apnoeas, whereas the number of obstructive apnoeas and hypopnoeas did not significantly differ from the selection night. They argued that ACET induces a resetting of the central chemoreceptor drive, which may continue after the cessation of drug therapy. This finding could not be confirmed in the present study, as the patients were only treated for a period of 4 weeks, compared to 5 months in the study by VERBRAECKEN et al. [17]. Furthermore, hypercapnic COPD patients were included in the current study instead of patients with nonhypercapnic central sleep apnoea syndrome.

In conclusion, the present study shows that shortterm combined treatment with medroxyprogesterone acetate and acetazolamide ( 2 weeks), in hypercapnic chronic obstructive pulmonary disease patients, can normalise arterial blood gas values and can improve nocturnal saturation and the chemical drive with a relative modest increase in minute ventilation. The combination of medroxyprogesterone acetate and acetazolamide is more beneficial than with either drug alone. It remains to be established whether longterm combined treatment in hypercapnic patients will postpone long-term oxygen therapy, postpone noninvasive ventilation, or even improve life expectancy.

\section{References}

1. Cooper C, Waterhouse J, Howard P. Twelve year clinical study of patients with hypoxic cor pulmonale given long term domiciliary oxygen therapy. Thorax 1987; 42: 105-110.

2. Aida A, Miyamoto K, Nishimura M, Aiba M, Kira S, Kawakami Y. Prognostic value of hypercapnia in patients with chronic respiratory failure during longterm oxygen therapy. Am J Respir Crit Care Med 1998; 158: 188-193.

3. Foucher P, Baudouin N, Merati M, et al. Relative survival analysis of 252 patients with COPD receiving long-term oxygen therapy. Chest 1998; 113: 15801587.

4. Karpel J, Aldrich T. Respiratory failure and mechanical ventilation: Pathophysiology and methods of promoting weaning. Lung 1986; 164: 309-324.

5. Claman D, Piper A, Sanders M, Stiller R, Votteri B. Nocturnal noninvasive positive pressure ventilatory assistance. Chest 1996; 128: 2610-2617.

6. Heijdra YF, Dekhuijzen PNR, van Herwaarden CLA, Folgering HTM. Nocturnal saturation improves by target-flow inspiratory muscle training in patients with COPD. Am J Respir Crit Care Med 1996; 153: 260265.

7. Vos PJE, Folgering HTM, Boo TM, de Lemmens WJGM, van Herwaarden CLA. Effects of chlormadinone acetate, acetazolamide and oxygen on awake and asleep gas exchange in patients with chronic obstructive pulmonary disease (COPD). Eur Respir J 1994; 7: $850-855$.

8. Hudgel D, Thanakitcharu S. Pharmacologic treatment of sleep-disordered breathing. Am J Respir Crit Care Med 1998; 158: 691-699.

9. DeBacker WA, Verbraecken J, Willemen $M$, Wittesaele W, DeCock W, van de Heyning P. Central apnea index decreases after prolonged treatment with acetazolamide. Am J Respir Crit Care Med 1995; 151: 87-91.

10. Wagenaar M, Teppema LJ, Berkenbosch A, Olievier CN, Folgering HTM. The effect of low-dose acetazolamide on the ventilatory $\mathrm{CO}_{2}$ response curve in the anaesthetized cat. J Physiol (London) 1996; 495: 227-237.

11. Wagenaar M, Teppema LJ, Berkenbosch A, Olievier CN, Folgering HTM. The effect of low dose acetazolamide on the ventilatory $\mathrm{CO}_{2}$-response during hypoxia in the anaesthetized cat. Eur Respir $J$ 1998; 12: 1271-1277.

12. Wagenaar M, Teppema LJ, Berkenbosch A, Olievier CN, Folgering HTM. Medroxyprogesterone acetate with acetazolamide stimulates breathing in cats. Respir Physiol 2000; 119: 19-29.

13. Dolly FR, Block AJ. Medroxyprogesterone acetate 
and COPD. Effect on breathing and oxygenation in sleeping and awake patients. Chest 1983; 84: 394-398.

14. Skatrud JB, Dempsey JA. Relative effectiveness of acetazolamide versus medroxyprogesterone acetate in correction of chronic carbon dioxide retention. Am Rev Respir Dis 1983; 127: 405-412.

15. Bayliss DA, Millhorn DE. Central neural mechanisms of progesterone action: application to the respiratory system. J Appl Physiol 1992; 73: 393-404.

16. Zwillich CW, Natalino MR, Sutton FD, Weil JV. Effects of progesterone on chemosensitivity in normal men. J Lab Clin Med 1978; 92: 262-269.

17. Verbraecken J, Willemen M, De Cock W, Coen E, van de Heyning P, De Backer W. Central sleep apnea after interrupting longterm acetazolamide therapy. Respir Physiol 1998; 112: 59-70.

18. Saifakas NM, Vermeire P, Pride NB, et al. Optimal assessment and management of chronic obstructive pulmonary disease (COPD). Eur Respir J 1995; 8: 1398-1420.

19. Quanjer PH, Tammeling GJ, Cotes JE, et al. Standardization of Lung Function Tests (working party "standardization of lung function tests", European Community for Steel and Coal.). Eur Respir J 1993; 16: Suppl. 16, 1-100.

20. Wilson SH, Cooke NT, Edwards RH, Spiro SG. Predicted normal values for maximal respiratory pressures in caucasian adults and children. Thorax 1984; 39: 535-538.

21. Folgering HTM. Studying the control of breathing in man. Eur Respir J 1988; 1: 651-660.

22. Surveillance for respiratory hazards in the occupational setting (American Thoracic Society). Am Rev Respir Dis 1982; 126: 952-956.

23. Swenson ER, Hughes JMB. Effects of acute and chronic acetazolamide on resting ventilation and ventilatory responses in men. J Appl Physiol 1993; 74: 230-237.

24. Daskalopoulou E, Patakas D, Tsara V, Zoglopitis F, Maniki E. Comparison of almitrine bismesylate and medroxyprogesterone acetate on oxygenation during wakefulness and sleep in patients with chronic obstructive lung disease. Thorax 1990; 45: 666-669.

25. Teppema LJ, Dahan A. Acetazolamide and breathing. Does a clinical dose alter peripheral and central $\mathrm{CO}_{2}$ sensitivity? Am J Respir Crit Care Med 1999; 160: 1592-1597.

26. Tojima H, Kunitomo F, Okita S, et al. Difference in the effects of acetazolamide and ammonium chloride acidosis on ventilatory responses to $\mathrm{CO}_{2}$ and hypoxia in humans. Jpn J Physiol 1986; 36: 511-521.

27. Moore LG, McCullough GE, Weil JV. Increased HVR in pregnancy: Relationship to hormonal and metabolic changes. J Appl Physiol 1987; 62: 156-163.

28. Whitelaw WA, Derenne J-P. Airway occlusion pressure. J Appl Physiol 1993; 74: 1475-1483.

29. Kiwull-Schone HF, Teppema LJ, Kiwull PJ. Lowdose acetazolamide does affect respiratory muscle function in spontaneously breathing anesthetized rabbits. Am J Respir Crit Care Med 2001; 163: 478483.

30. Contreras G, Gutierrez M, Beroiza T, et al. Ventilatory drive and respiratory muscle function in pregnancy. Am Rev Respir Dis 1991; 144: 837-841.

31. Swenson ER. Carbonic anhydrase inhibitors and ventilation: a complex interplay of stimulation and suppression (editorial). Eur Respir J 1998; 12: 1242 1247.

32. Chaouat A, Weitzenblum E, Kessler R, et al. Outcome of COPD patients with mild daytime hypoxaemia with or without sleep-related oxygen desaturation. Eur Respir J 2001; 17: 848-855. 